\title{
ARTICLE
}

\section{Loss of the vitamin D receptor in human breast and prostate cancers strongly induces cell apoptosis through downregulation of Wnt/ $\beta$-catenin signaling}

\author{
Yu Zheng ${ }^{1 *}$, Trupti Trivedi ${ }^{1 *}$, Ruby CY Lin ${ }^{2,3}$, Colette Fong-Yee ${ }^{1}$, Rick Nolte ${ }^{1}$, Jeline Manibo ${ }^{1}$, Yunzhao Chen ${ }^{1,4}$,
} Musharraf Hossain ${ }^{4}$, Konstantin Horas ${ }^{1}$, Colin Dunstan ${ }^{5}$, Hong Zhou ${ }^{1,6}$ and Markus J Seibel ${ }^{1,6}$

Vitamin D co-regulates cell proliferation, differentiation and apoptosis in numerous tissues, including cancers. The known anti-proliferative and pro-apoptotic actions of the active metabolite of vitamin $\mathrm{D}$, 1,25-dihydroxy-vitamin $\mathrm{D}\left[1,25(\mathrm{OH})_{2} \mathrm{D}\right]$ are mediated through binding to the vitamin $\mathrm{D}$ receptor (VDR). Here, we report on the unexpected finding that stable knockdown of VDR expression in the human breast and prostate cancer cell lines, MDA-MB-231 and PC3, strongly induces cell apoptosis and inhibits cell proliferation in vitro. Implantation of these VDR knockdown cells into the mammary fat pad (MDA-MB-231), subcutaneously (PC3) or intra-tibially (both cell lines) in immune-incompetent nude mice resulted in reduced tumor growth associated with increased apoptosis and reduced cell proliferation compared with controls. These growth-retarding effects of VDR knockdown occur in the presence and absence of vitamin D and are independent of whether cells were grown in bone or soft tissues. Transcriptome analysis of VDR knockdown and non-target control cell lines demonstrated that loss of the VDR was associated with significant attenuation in the $\mathrm{Wnt} / \boldsymbol{\beta}$-catenin signaling pathway. In particular, cytoplasmic and nuclear $\beta$-catenin protein levels were reduced with a corresponding downregulation of downstream genes such as Axin2, Cyclin D1, interleukin-6 (IL-6), and IL-8. Stabilization of $\beta$-catenin using the GSK-3 $\beta$ inhibitor BIO partly reversed the growth-retarding effects of VDR knockdown. Our results indicate that the unliganded VDR possesses hitherto unknown functions to promote breast and prostate cancer growth, which appear to be operational not only within but also outside the bone environment. These novel functions contrast with the known anti-proliferative nuclear actions of the liganded VDR and may represent targets for new diagnostic and therapeutic approaches in breast and prostate cancer.

Bone Research (2017) 5, 17023; doi:10.1038/boneres.2017.23; published online: 5 September 2017

\section{INTRODUCTION}

Breast and prostate cancers are among the most prevalent malignancies in industrialized countries. Although mortality has steadily declined over the past 20 years, a significant proportion of patients eventually develop metastatic disease, most frequently to the skeleton. ' Skeletal related events due to bone metastasis are frequent and a major cause of mortality and morbidity. ${ }^{2-3}$
We have previously shown in rodent models that reduced bone turnover inhibits, while increased bone turnover accelerates, breast and prostate cancer growth in bone..$^{4-10}$ These experimental findings provide a logical explanation for the clinical observation that accelerated bone turnover is associated with higher rates of skeletal related events and poorer prognosis in patients with breast or prostate cancer. ${ }^{11}$ They also offer a rationale for the use

\footnotetext{
'Bone Research Program, ANZAC Research Institute, Sydney, New South Wales, Australia; ${ }^{2}$ Asbestos Diseases Research Institute, Cardiothoracic Genomics, Sydney, New South Wales, Australia; ${ }^{3}$ School of Medical Sciences, University of New South Wales, Sydney, New South Wales 2052, Australia; ${ }^{4}$ Department of Pathology, Shihezi University School of Medicine, Shihezi, China; ${ }^{5}$ Biomedical Engineering, AMME, University of Sydney, Sydney, New South Wales, Australia and ${ }^{6}$ Concord Clinical School, The University of Sydney, Sydney, New South Wales, Australia Correspondence: Markus J Seibel (markus.seibel@sydney.edu.au)

*These authors contributed equally to this work.

Received: 3 January 2017; Revised: 20 February 2017; Accepted: 19 March 2017
} 
of anti-resorptive agents in these patients. ${ }^{12}$ We have further reported that in rodent models, vitamin D deficiency promotes the growth of breast and prostate cancer cells in bone. ${ }^{5,8,10,13}$ These effects appear to be mediated mainly through an increase in bone remodeling, that is, indirectly through changes in the bone microenvironment. However, inhibition of bone remodeling with potent anti-resorptive treatments (for example, osteoprotegerin, zoledronic acid) fails to completely reverse the pro-proliferative effects of vitamin D deficiency, 8,10 suggesting that vitamin $D$ deficiency may also promote cancer cell growth by an additional and possibly direct mechanism.

Apart from its function in calcium and phosphate homeostasis, vitamin $D$ is known to exert strong antiproliferative, pro-differentiation and pro-apoptotic actions in numerous cell types and tissues, including cancers. ${ }^{14}$ The biologically active metabolite of vitamin D, 1,25-dihydroxyvitamin $\mathrm{D}\left[1,25(\mathrm{OH})_{2} \mathrm{D}\right]$, acts through binding to the vitamin $D$ receptor (VDR), a member of the nuclear steroid hormone receptor superfamily. In the absence of vitamin $D$, the VDR remains in the cytoplasm. Ligand binding causes the VDR to form a heterodimer with the retinoid $X$ receptor, which facilitates movement of the VDR-ligand complex out of the cytoplasm and into the nucleus. Within the nucleus this complex binds to vitamin D-responsive elements in the regulatory region of target genes. ${ }^{15}$ In keeping with the classical function of vitamin $D$ in regulating calcium and phosphate homeostasis, the VDR is expressed at high levels in tissues such as the intestine, bone and kidney. ${ }^{15}$ However, research into the pleiotropic actions of vitamin D has revealed that the VDR is also expressed in numerous other tissues, including malignant tumors. ${ }^{14}$ Limited clinical studies in patients with breast and prostate cancer demonstrated that VDR expression in these tumors is negatively associated with tumor size and lymph node involvement. ${ }^{16-18}$ Furthermore, mice with global VDR knock-out show increased sensitivity to carcinogen challenges. ${ }^{14,19-20}$ These and the findings of our previous studies ${ }^{8,10}$ point to a broader role of the VDR in the regulation of cell growth, which may go beyond its classical function as a ligand-specific nuclear receptor. Using a VDR knockdown approach, the current in vitro and in vivo studies aimed to further define the role of the VDR in the regulation of breast and prostate cancer growth.

\section{MATERIALS AND METHODS}

Cell culture

The human breast cancer cell line, MDA-MB-231, ${ }^{21}$ was obtained from ATCC. Cells were cultured in Dulbecco's Modified Eagle's medium, supplemented with 10\% fetal bovine serum (FBS, JRH Biosciences, KS, USA) and $1 \%$ penicillin-streptomycin. The human prostate cancer cell line, PC3, was obtained from ATCC. Cells were cultured in RPMI, supplemented with $10 \%$ fetal bovine serum (FBS, JRH Biosciences, Lenexa, Kansas, USA) and $1 \%$ penicillinstreptomycin solution. Unless otherwise stated, tissue culture media and supplements were from Life Technologies (Carlsbad, CA, USA).

\section{Knockdown of VDR expression in cancer cells}

VDR expression was silenced in MDA-MB-231 and PC3 cells via a lentiviral-based expression system driving the production of short hairpin RNA species (shRNAs, Sigma, St. Lovis, MO, USA). The clones selected were VDR (referred as "VDR-KD", transfected with shRNA, TRCN000019506, Sigma) and non-target control (referred as "NT", transfected with non-target RNA, SHCO02V, Sigma). VDR-KD and NT cells from both MDA-MB-231 and PC3 cells were selected using $2 \mu \mathrm{g} \cdot \mathrm{mL}^{-1}$ puromycin (Sigma, USA) for two weeks. The cells resulting from this transfection will be referred to as MDA-NT, MDA-VDR-KD, PC3-NT, and PC3-VDR-KD.

\section{Cell growth assays}

NT and VDR-KD cells were treated with $10^{-8} \mathrm{~mol} \cdot \mathrm{L}^{-1} \quad 1,25-$ dihydroxy vitamin $D_{3}\left[1,25(\mathrm{OH})_{2} D_{3}\right]$ or vehicle $10.1 \%$ ethanol) in medium supplemented with $2 \%$ charcoal stripped heat-inactivated fetal bovine serum (FBS). In our hands, untreated FBS contains $1,25(\mathrm{OH})_{2} \mathrm{D}$ at a concentration of $360 \mathrm{pmol} \cdot \mathrm{L}^{-1}$ when measured by RIA (Diasorin, Stillwater, MN, USA). In contrast, $1,25(\mathrm{OH})_{2} \mathrm{D}$ is undetectable in media supplemented with $2 \%$ charcoal stripped heat-inactivated FBS. We therefore consider culture media supplemented with $2 \%$ charcoal stripped heat-inactivated serum to be free of $1,25(\mathrm{OH})_{2} \mathrm{D}$ ("ligand-free media"). Cell growth assays were performed as described previously. ${ }^{6,22}$ Briefly, cells were seeded in media containing $2 \%$ charcoal stripped FBS and treated with either $10^{-8} \mathrm{~mol} \cdot \mathrm{L}^{-1}, 1,25$ $(\mathrm{OH})_{2} \mathrm{D}_{3}$ or vehicle. For the rescue experiments, cells were treated in the same manner with $1 \mu \mathrm{mol} \cdot \mathrm{L}^{-1}$ 6-bromoindirubin-3'-oxime (BIO, Sigma), a compound that binds to, and inactivates the enzyme that normally phosphorylates

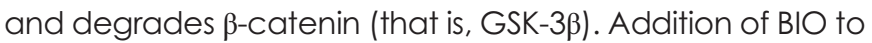
the cell culture inhibits this process and therefore stabilizes $\beta$-catenin signaling, ${ }^{23}$ allowing for $\beta$-catenin to translocate to the nucleus and maintain Wnt/ $\beta$-catenin signaling in VDR-KD cells. Media were replaced every $24 \mathrm{~h}$ and cells were counted daily by trypan blue exclusion until reaching $100 \%$ confluence on day four. Experiments were repeated three times in independent settings to ensure validity of the results.

Cell apoptosis assay

NT and VDR-KD cells were cultured in medium containing $2 \%$ charcoal stripped FBS and treated with either $0.1 \%$ 
Table 1. Primers used in this article

\begin{tabular}{|c|c|}
\hline Primers & Sequence $\left(5^{\prime}-3^{\prime}\right)$ \\
\hline hGAPDH & $\begin{array}{l}\text { F: TATGACAACGAATTTGGCTACAG } \\
\text { R: TGATGGTACATGACAAGGTGC }\end{array}$ \\
\hline hVDR & $\begin{array}{l}\text { F: ACCTGGACAACAAGAGCGA } \\
\text { R: CTCCTTCCTTCTCCTTCTGATG }\end{array}$ \\
\hline hCYP24 & $\begin{array}{l}\text { F: GCATCTTCCATTTGGCGT } \\
\text { R: AATACCACCATCTGAGGCGT }\end{array}$ \\
\hline Cyclin D1 & $\begin{array}{l}\text { F: AGAACACGGCTCACGCTTA } \\
\text { R: ATCCAGGACTTGTGCCCTT }\end{array}$ \\
\hline Caspase 3 & $\begin{array}{l}\text { F: CAGCACCTGGTTATTATTCTTGG } \\
\text { R: TGTCGGCATACTGTTTCAGC }\end{array}$ \\
\hline Wnt3a & $\begin{array}{l}\text { F:CTCTCCCTCTCTCTCATCTTACATTT } \\
\text { R: GCCTCAGGTCTGTTCCTATCA }\end{array}$ \\
\hline FZD4 & $\begin{array}{l}\text { F: ATTCCCACCACAGAACGAC } \\
\text { R: CATAGCCACACTTGAGCACAC }\end{array}$ \\
\hline TCF7 & $\begin{array}{l}\text { F: CTGCCCAGGTGACTGACTAAT } \\
\text { R: GATTGAAGGCGGAGTAGACG }\end{array}$ \\
\hline Axin2 & $\begin{array}{l}\text { F: AGACGGTGCTTACCTGTTCC } \\
\text { R: GCTGCTTGGAGACAATGCT }\end{array}$ \\
\hline hlL-6 & $\begin{array}{l}\text { F: GCATTCCTTCTTCTGGTCAG } \\
\text { R: GCCATTTATTTGAGGTAAGCC }\end{array}$ \\
\hline hlL-8 & $\begin{array}{l}\text { F: AGACAGCAGAGCACACAAGC } \\
\text { R: CACTGGCATCTTCACTGATTCT }\end{array}$ \\
\hline $\mathrm{SHH}$ & $\begin{array}{l}\text { F: CAGAAACTCCGAGCGATTT } \\
\text { R: GCCAAAGCGTTCAACTTGT }\end{array}$ \\
\hline EEF1A2 & $\begin{array}{l}\text { F: CACATCAACATCGTGGTCA } \\
\text { R: CGAACTTCTCAATGGTCCTTT }\end{array}$ \\
\hline Ki67 & $\begin{array}{l}\text { F: ACGTCGTGTCTCAAGATCTAGC } \\
\text { R: AACGGCTCACTAATTTAACGC }\end{array}$ \\
\hline
\end{tabular}

ethanol or $10^{-8} \mathrm{~mol} \cdot \mathrm{L}^{-1} \quad 1,25(\mathrm{OH})_{2} \mathrm{D}_{3}$ for 6 days as described above. For the rescue experiment, cells were treated with vehicle or $1 \mu \mathrm{mol} \cdot \mathrm{L}^{-1} \mathrm{BIO}$ for $24 \mathrm{~h}$, allowing for stabilization of $\beta$-catenin in VDR-KD cells. Apoptosis was measured by TUNEL assay using an in situ cell death detection kit (POD, Roche Pharmaceutical, Manheim, Germany). TUNEL-positive and total cells were counted in 3-5 random fields/well at 400X magnification.

Transcriptome analysis and Quantitative RT-PCR

Total RNA was extracted from MDA-NT $(n=3)$ and MDAVDR-KD $(n=3)$ cell cultures and was labeled and hybridized onto Affymetrix Human GeneChip Gene 2.1 ST arrays (Affymetrix, Santa Clara, CA, USA), according to the manufacturer's instructions (Ramaciotti Centre for Genomics, University of New South Wales). Interrogating probes were imported and normalized using RMA algorithm and RMA background corrected. One-way ANOVA was carried out to extract significantly differentially expressed genes at unadjusted $P<0.05$ level. Principle component analysis indicated that these cell lines had distinctive gene expression profiles (data not shown). Pathway enrichment analysis was then carried out on the top 150 differentially expressed genes to characterize and compare the biological pathways best represented in both cell types and affected by VDR-KD. The genes are ordered by their $P$-values and based on the Kyoto Encyclopedia of Genes and Genomes (KEGG). These genes are compared to the database which consists of hundreds of carefully constructed, publicly available and curated pathway networks reflecting accumulated biological data from the field. Using Fisher's Exact test at $P<0.01$, these top 150 genes were embedded and compared within the network structure. Accordingly, under the null hypothesis, Fisher's Exact test was used to establish whether or not the candidate genes are associated with the pathway. The higher the enrichment score the more enriched the genes are within a specific pathway. This enabled us to infer a VDR-KD effect at the systems level ${ }^{24}$ and identify specifically which essential regulatory pathways are affected. To further validate the array data, cDNA was generated from the same RNA samples using Super Script III (Life Technologies). Expression levels of candidate genes were assessed by real-time RT-PCR. Primer sequences are listed in Table 1. GADPH was used for normalization.

Western blot analysis

For protein expression, cells were harvested at $24 \mathrm{~h}$ post plating. Whole cell lysates were prepared using RIPA buffer and cell fractions were prepared using NE-PER Nuclear and Cytoplasmic Extraction kit (Thermo Scientific, Rockford, IL, USA), supplemented with protease inhibitor cocktail (Roche Pharmaceutical). Protein concentrations were determined using a Pierce $660 \mathrm{~nm}$ protein assay (Thermo Scientific), proteins were separated on Bolt $4 \%-12 \%$ mini gels and then transferred onto nitrocellulose membrane by means of the iBlot2 rapid transfer (Life Technologies).

Membranes were blocked in TBS-T 5\% skim milk for $1 \mathrm{~h}$, incubated overnight with primary antibody and then with secondary antibody for $1 \mathrm{~h}$. Proteins were visualized with Amersham ECL Western Blotting Detection Reagents (GE Healthcare, Amersham, Buckinghamshire, UK) and detected with the Bio-Rad Image Lab system (Bio-Rad, Hercules, California, USA). Primary antibodies used were: anti-VDR (Clone 9A7 $\gamma . E 10 . E 4$, Thermo Scientific, Rockford, IL, USA), anti- $\beta$-catenin, anti- $\beta$-actin, (Cell Signaling Technology, Danvers, MA, USA), GSK-3 $\beta$ (BD Biosciences, Franklin Lakes, NJ, USA), and anti-caspase 3 (Merck Millipore, Frenchs Forest, NSW, Australia).

\section{Animal models}

Five-week-old female and male BALB/C nu/nu mice were purchased from the Animal Resources Centre, Canning Vale, WA, Australia. Previously studies in our laboratory confirmed these mice to be fully replete for 25(OH)D levels. ${ }^{8,10}$ Murine xenograft models were employed to 
study breast (MDA-MB-231, female mice) or prostate (PC3, male mice) cancer cell growth in bone and, orthotopically, in either the mammary fat pads (female mice) or the subcutaneous tissue of the inferior-lateral flank (male mice), as described previously. ${ }^{6,22}$ In accordance with Animal Welfare Guidelines and approved protocols, all mouse manipulations were performed inside a laminar-flow hood under aseptic conditions whilst maintaining general anesthesia following intra-peritoneal injection of ketamine/ xylazine $\left(75 / 10 \mathrm{mg} \cdot \mathrm{kg}^{-1}\right)$. The analgesic carprofen (Rimadyl) (5 $\mathrm{mg} \cdot \mathrm{kg}^{-1}$ subcutaneously) was administered before inoculation to minimize post-surgical pain.

For the orthotopic and subcutaneous models, cells were prepared as above and suspended in a mixture of cold Matrigel and PBS (1:1) at a concentration of $1 \times 10^{7}$ cells per $\mathrm{mL} .100 \mu \mathrm{L}$ of the suspension was either implanted orthotopically into the mammary fad pad or subcutaneously at the flank ( $n=8-10$ per group). Tumor growth was measured by calipers every second day from day 6 onwards and tumor volume was determined using the modified ellipsoidal formula [volume $=\left(\right.$ length $\times$ width $\left.^{2}\right) / 2$ ]. For the intratibial xenograft model, $10 \mu \mathrm{L}$ of cell suspension (for MDA, $5 \times 10^{4}$ cells per injection, for PC3 cells $10^{5}$ cells per injection) were slowly injected through the tibial plateau of the left proximal tibia using a Hamilton syringe.? Contralateral tibiae were injected similarly with vehicle alone (PBS). For the monitoring of lytic bone lesions in vivo, mice were anesthetized as above and assessed by digital radiography: for MDA cells, images were taken on days 10, 17 and 21 post cell injection; for PC3 cells, images were taken on days 17, 24 and 31 post cell injection. Lytic bone areas within the tibiae were measured using interactive image analysis software (ImageJ, NIH, Bethesda, Maryland, USA) and the size of osteolytic lesions was calculated. The growth of lytic lesions was compared among experimental groups. The intratibial experiments were terminated before mice showed adverse effects of the tumor growth.

Histological staining and immunohistochemistry

Tibiae were fixed for $36 \mathrm{~h}$ in $4 \%$ paraformaldehyde buffered with $0.1 \mathrm{~mol} \cdot \mathrm{L}^{-1}$ phosphate buffer $(\mathrm{pH} 7.4)$ and decalcified in $10 \%$ EDTA at $4{ }^{\circ} \mathrm{C}$ for 2 weeks. The tissues were then processed and embedded in paraffin. Four-micron sections were cut from each specimen and stained with haematoxylin and eosin for routine histological examination. Osteoclasts were detected via histochemical analysis of tartrate-resistant acid phosphatase (TRACP), using naphthol AS-MX phosphate as substrate and fast red violet Luria-Bertani salt (both from Sigma Chemical, St. Louis, MA, USA) as a stain for the reaction product; incubation was performed at room temperature for $30 \mathrm{~min}$.
Apoptotic cells were identified using terminal deoxynucleotidyl transferase-mediated dUTP nick end labeling (TUNEL) (ApopTaq Peroxidase In Situ Apoptosis Detection Kit, Millipore, Temecula, CA, USA). For immunohistochemistry, antigen retrieval was achieved by immersing sections in $10 \mathrm{mmol} \cdot \mathrm{L}^{-1}$ citric acid at $70^{\circ} \mathrm{C}$ for 90 minutes. The following rabbit polyclonal antibodies and dilutions were used: Ki67 (NeoMarkers, Fremont, CA, USA, 1:200), VDR (Chemicon, AB3786, Temecula, CA, USA, 1:200), and $\beta$-catenin (Cell Signaling, 1:500). Signals were detected using biotinylated goat anti-rabbit secondary antibodies (Vectastain ABC-Peroxidase Kits, Vector Laboratories, Burlingame, CA, USA) and DAB (Vector Laboratories). All sections were counterstained with Harris Hematoxylin.

Micro-computed tomography imaging

After tissue harvest, representative micro-computed tomography (CT) images of tibiae were obtained using a SkyScan 1172 scanner (SkyScan). Scanning was done at $100 \mathrm{kV}, 100 \mu \mathrm{A}$ using a 1-mm aluminum filter. In total, 1800 projections were collected at a resolution of $6.93 \mu \mathrm{m}$ per pixel. Reconstruction of sections was done using a modified Feldkamp cone-beam algorithm with beam hardening correction set to 50\%. VGStudio MAX software (Volume Graphics $\mathrm{GmbH}$ ) was used to obtain three-dimensional visualization of tibiae from reconstructed sections.

Bone histomorphometry

Histomorphometric analysis of the proximal tibial metaphysis was conducted to evaluate bone volume, tumor burden and static measures of bone resorption. Measurements were performed in longitudinal $4 \mu \mathrm{m}$ thick sections stained with haematoxylin and eosin ( $\times 12.5$ magnification) using the OsteoMeasure System (Osteometrics, Atlanta, GA, USA). Multiple sagittal sections were cut through each tibial sample and stained. The sagittal section with largest tumor area was selected and the tumor area was measured and used as an index of tumor burden. Cortical bone area was measured in the same sections. Osteoclasts were identified as TRACP-positive multinucleated cells at the tumor-bone interface. The number of osteoclasts per millimeter of tumor-bone interface was calculated at a magnification of $\times 200$.

Statistical analysis

All data were presented as the mean \pm SE. Statistical analyses were conducted using one-way ANOVA followed by Bonferroni's adjustment where there were multiple comparisons (SPSS 17.0 for Windows, SPSS, Chicago, IL, USA). Significance was accepted at $P<0.05$. 
a

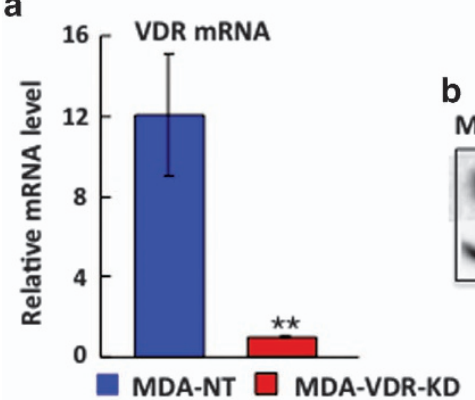

d
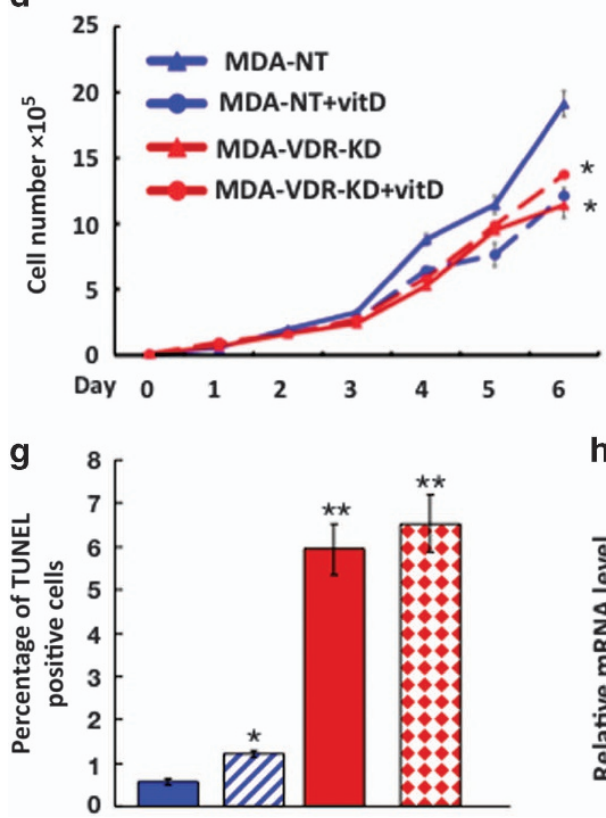

h
MDA-NT MDA-VDR-KD

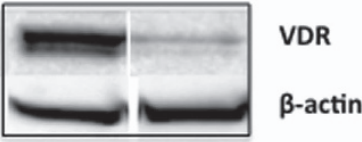

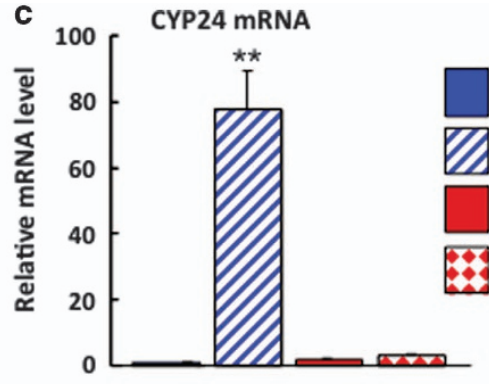

MDA-NT

MDA-NT + vitD

MDA-VDR-KD

MDA-VDR-KD + vitD
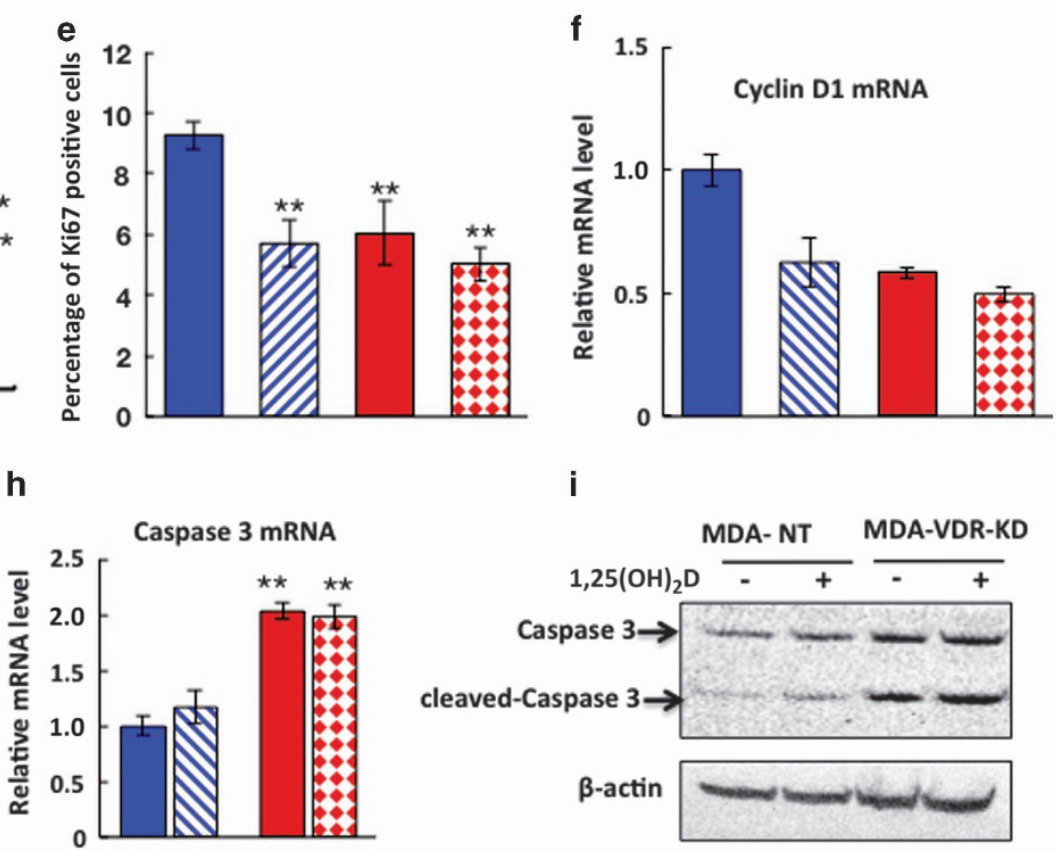

i

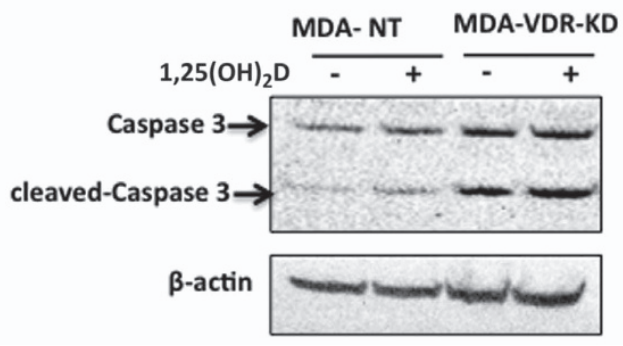

Figure 1. VDR knockdown in MDA-MB-231 cells reduces cell growth in vitro in a ligand-independent manner. (a,b) Compared to non-target controls (MDA-NT, cells transfected with non-target RNA), VDR mRNA (a) and protein (b) expression were knocked down by approximately 80\% in MDAVDR-KD cells at $24 \mathrm{~h}$ post plating. ${ }^{* *} P<0.01$. (c) Treatment of MDA-NT and MDA-VDR-KD cells with $10^{-8} \mathrm{~mol} \cdot \mathrm{L}^{-1} 1,25(\mathrm{OH})_{2} \mathrm{D}_{3}$ for $8 \mathrm{~h}$ increased CYP24 expression by 80-fold in MDA-NT cells with no appreciable response in MDA-VDR-KD cells. ${ }^{* *} P<0.01$ compared to baseline. (d-i) Culture of MDA-NT and MDA-VDR-KD cells under ligand-free conditions: Compared to NT cells, cell growth (d) and cell proliferation (Ki67 immunoreactivity, (e) as well as Cyclin D1 mRNA of VDR-KD cells (f) were reduced by 40\%, 36\% and 50\%, respectively. However, apoptosis was increased 6-fold (g) and Caspase 3 mRNA and protein was increased by $50 \%(\mathbf{h}, \mathbf{i})$. Treatment of MDA-NT cells with $10^{-8}$ mol $\cdot \mathrm{L}^{-1} 1,25(\mathrm{OH})_{2} \mathrm{D}_{3}$ reduced both cell growth $(\mathbf{d})$, Ki67 positivity (e) and Cyclin D1 mRNA expression (f) and induced a 2-fold increase in cell apoptosis (g) as well as Caspase 3 mRNA and protein expression $(\mathbf{h}, \mathbf{i})$ compared to untreated MDA-NT cells. In contrast, the same treatment had no effect on the growth or apoptosis rates of MDA-VDR-KD cells $(\mathbf{d}-\mathbf{i})$. Asterisks denote significant difference from untreated MDA-NT cells $\left({ }^{*} P<0.05 ;{ }^{* *} P<0.01\right)$. In vitro experiments were performed in triplicate and repeated at least three times. Results shown are from a single representative experiment. Data are expressed as mean \pm s.e.m. $(n=3)$.

\section{RESULTS}

Knockdown of VDR expression in MDA-MB-231 cells

Relative to shRNA non-target controls (MDA-NT cells transfected with non-target RNA), knockdown efficiency in MDAVDR-KD cells was $\sim 80 \%$ at the mRNA and protein level at $24 \mathrm{~h}$ post plating (Figure la and b). To assess VDR ablation on a functional basis, MDA-VDR-KD and MDA-NT cells $24 \mathrm{~h}$ post plating were treated for $8 \mathrm{~h}$ with $10^{-8} \mathrm{~mol} \cdot \mathrm{L}^{-1} 1,25(\mathrm{OH})_{2} \mathrm{D}_{3}$ in media supplemented with $2 \%$ charcoal stripped heatinactivated fetal bovine serum and the expression of CYP24, a downstream target gene of the classical VDR signaling pathway, was measured. As expected, treatment with $1,25(\mathrm{OH})_{2} \mathrm{D}_{3}$ strongly induced CYP24 expression in MDANT cells (>75-fold). In contrast, MDA-VDR-KD cells demonstrated no significant change in CYP24 expression, confirming efficient abrogation of VDR signaling in these cancer cells (Figure 1c).

VDR knockdown in MDA-MB-231 cells reduces cell proliferation and increases cell apoptosis: in vitro studies As $1,25(\mathrm{OH})_{2} \mathrm{D}_{3}$ treatment suppresses cancer cell growth in vitro, and vitamin D deficiency enhances breast and prostate cancer growth in animal models of bone 
a

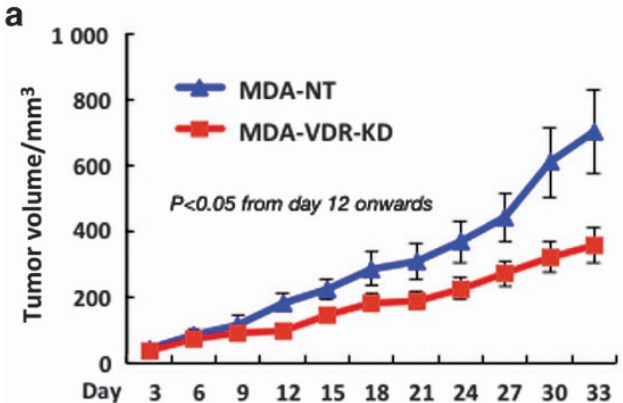

b

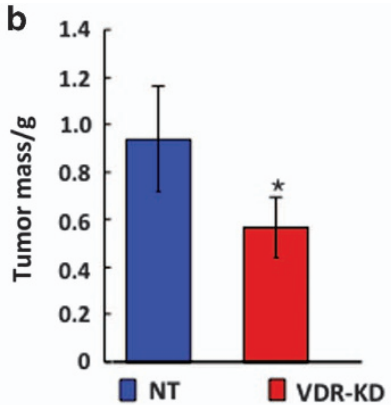

C

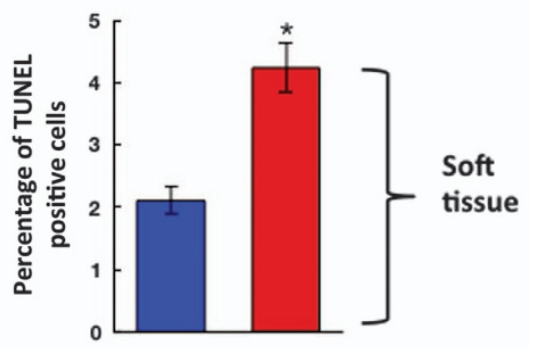

d

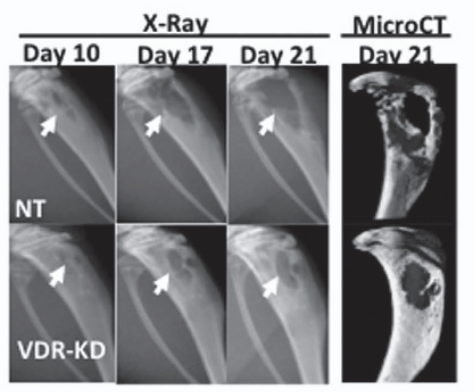

e

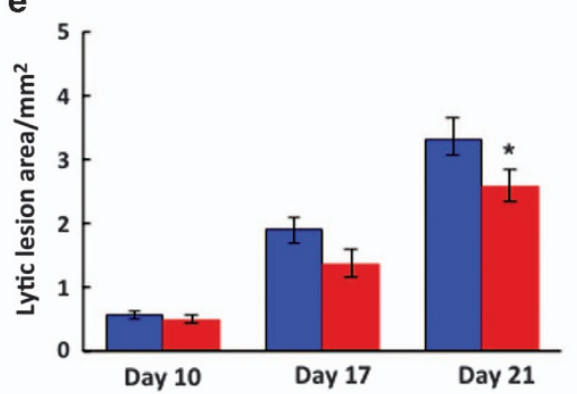

f

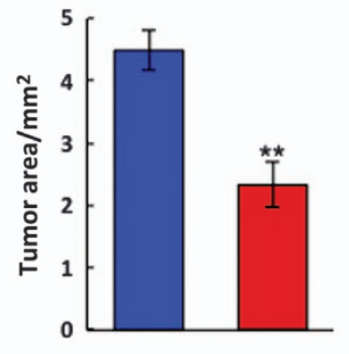

Bone

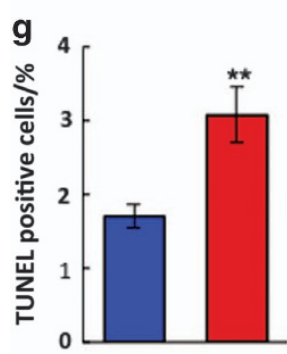

h

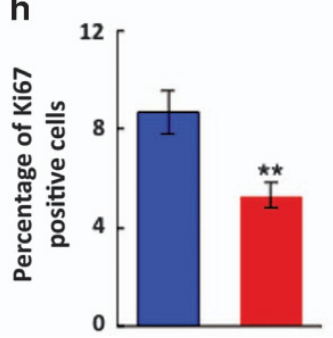

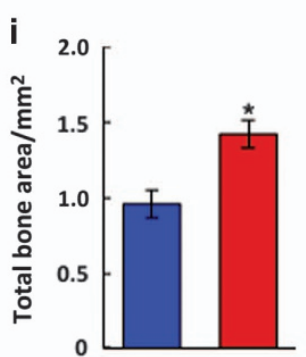
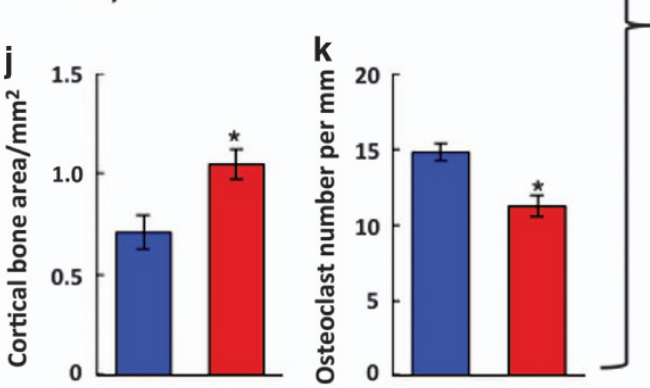

Figure 2. VDR knockdown in MDA-MB-231 cells reduces tumor growth in vivo. (a-c) Orthotopic implantation: When implanted into the mammary fat pad, tumors derived from MDA-VDR-KD cells grew significantly slower than those induced by MDA-NT cells $(n=10)(\mathbf{a})$. At study endpoint (day 33 post implantation), tumor weight (b) was reduced by $40 \%$ while the proportion of apoptotic cancer cells (c) was increased by $36 \%$ in MDA-VDR-KD compared to MDA-NT tumors $(n=10)$. Asterisks denote significant difference from controls $\left({ }^{*} P<0.05\right)$. Data are mean \pm s.e.m. (d-j) Intra-tibial implantation: At endpoint (day 21 post implantation) lytic lesion size on X-ray, micro-CT (d,e) and histological tumor area (f) were significantly smaller in mice implanted with MDA-VDR-KD than with MDA-NT cells $(n=15)$. Compared to NT controls, tumors derived from VDR knockdown cells were characterized by an increased proportion of apoptotic cancer cells (g) and lower mitotic activity (h). At the bone/tumor interface, tumors derived from VDR knockdown cells exhibited increased total and cortical bone area $(\mathbf{i}, \mathbf{j})$, and reduced osteoclast number $(\mathbf{k})$. Asterisks denote significant difference from MDA-NT $\left({ }^{*} P<0.05 ;{ }^{* *} P<0.01\right)$. Data are mean \pm s.e.m.

metastasis, $8,10,13$ we hypothesized that ablation of the VDR in human breast cancer cells would promote tumor growth. As expected, ${ }^{25}$ treatment of VDR-expressing MDA-NT cells with $10^{-8} \mathrm{~mol} \cdot \mathrm{L}^{-1} \quad 1,25(\mathrm{OH})_{2} \mathrm{D}_{3}$ significantly reduced in vitro cell growth (Figure $1 \mathrm{~d}$-f) and induced a 2 fold increase in apoptosis compared to MDA-NT cells (Figure 1g). Surprisingly, however, when cultured under ligand-free conditions the growth of MDA-VDR-KD cells was also significantly reduced, with growth curves similar to those of $1,25(\mathrm{OH})_{2} \mathrm{D}_{3}$ treated MDA-NT cells. As expected, treatment of VDR knockdown cells with $1,25(\mathrm{OH})_{2} \mathrm{D}_{3}$ had no further effect on growth (Figure 1d). Compared to NT controls, cell proliferation was significantly reduced in MDAVDR-KD cells, again of similar magnitude to that seen in
$1,25(\mathrm{OH})_{2} \mathrm{D}_{3}$-treated MDA-NT cells (Figure le and f). In contrast, VDR knockdown was associated with a pronounced rise in cell apoptosis: Thus, the proportion of TUNEL-positive cells was 12-fold higher in MDA-VDR-KD cells compared to MDA-NT controls (Figure 1g). In keeping with these observations, Caspase 3 mRNA expression and cleaved Caspase 3 protein levels were significantly higher in MDA-VDR-KD than NT cells (Figure $1 \mathrm{~h}$ and i).

VDR knockdown in MDA-MB-231 cells reduces cell growth: in vivo studies

In order to examine the effects of VDR knockdown in vivo, MDA-VDR-KD and MDA-NT cells were xenografted into vitamin D-replete nude mice either via orthotopic injection 
a

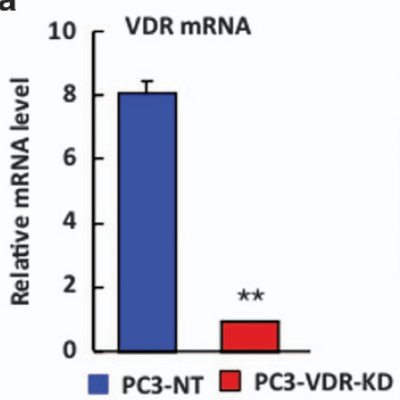

b PC3-NT PC3-VDR-KD

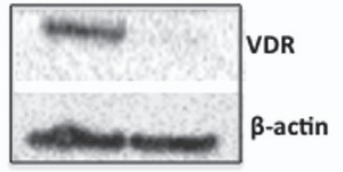

C

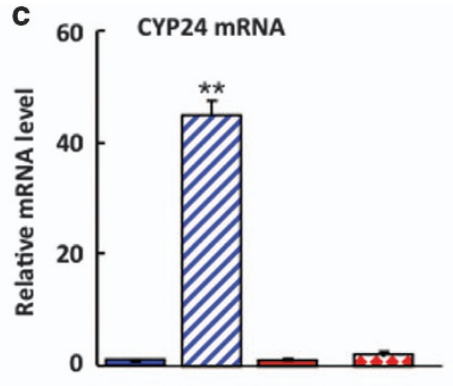

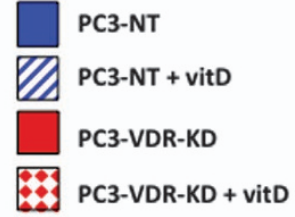

d

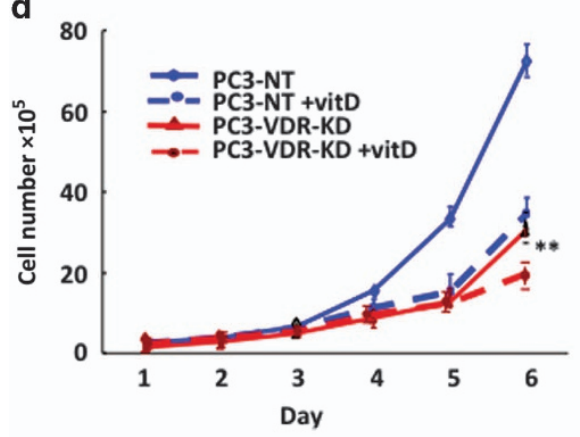

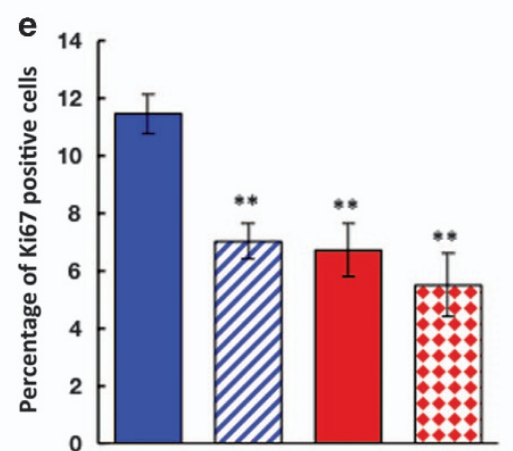

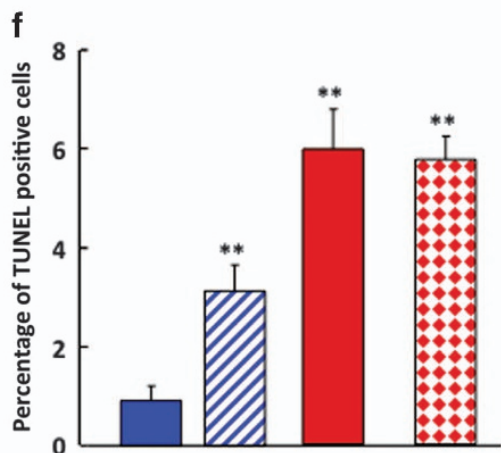

Figure 3. Effects of VDR knockdown in prostate cancer (PC3) cells - in vitro studies. (a,b) Compared to non-target controls (PC3-NT, cells transfected with non-target RNA), VDR mRNA (A) and protein (B) expression was knocked down by $80 \%$ in PC3-VDR-KD cells at $24 \mathrm{~h}$ post plating. ${ }^{* *} \mathrm{P}<0.001$. (c) Treatment of PC3-NT and PC3-VDR-KD cells with $10^{-8} \mathrm{~mol} \cdot \mathrm{L}^{-1} 1,25(\mathrm{OH})_{2} \mathrm{D}_{3}$ for $8 \mathrm{~h}$ increased CYP24 expression by more than $40-$ fold in NT cells with no appreciable response in knockdown cells. ${ }^{* *} P<0.001$ compared to baseline. (d-f): Culture of PC3-NT and PC3-VDR-KD cells under ligand-free conditions. Compared to NT cells, cell growth (d) and cell proliferation (Ki67 immunoreactivity, (e) of MDA-VDR-KD cells were reduced by $49 \%$ and $41 \%$, respectively, while apoptosis was increased to six fold (f). Treatment of PC3-NT cells with $10^{-8}$ mol $\cdot \mathrm{L}^{-1} 1,25(\mathrm{OH})_{2} \mathrm{D}_{3}$ reduced cell growth by $51 \%$ (d) and Ki67 positivity by $38 \%$ (e) while inducing a 3-fold increase in apoptosis (f) compared to untreated PC3-NT cells. In contrast, the same treatment had no effect on the growth or apoptosis rates of PC3-VDR-KD cells (d-f). ${ }^{*} P<0.05$; ${ }^{* *} P<0.01$ compared to respective controls. In vitro experiments were performed in triplicate and repeated at least three times. Results shown are from a single representative experiment. Data are expressed as mean \pm s.e.m. $(n=3)$.

into the mammary fat pad or by inoculation into the left tibia. $^{22}$

Following orthotopic implantation of MDA-MB-321 cells into the mammary soft tissue, VDR ablation was associated with significantly reduced tumor growth compared to VDR-expressing NT controls (Figure 2a). At endpoint (day 33 post implantation (p.i.)), tumor mass was $40 \%$ lower and apoptosis was $36 \%$ higher in tumors derived from MDAVDR-KD cells compared to those grown from MDA-NT cells $(n=10$ per group, $P<0.05$; Figure $2 \mathrm{~b}$ and $\mathrm{c}$ ).

When MDA-NT and MDA-VDR-KD cells were implanted into the tibiae, tumors derived from VDR knockdown cells produced significantly smaller lytic lesions (Figure $2 d$ and e) and tumor areas (Figure 2f) at endpoint (day 21 p.i.) than tumors generated by NT cells $(n=15, P<0.05)$. In keeping with these phenotypes, tumors derived from VDR knockdown cells contained a higher proportion of apoptotic cells $(+80 \%)$ and demonstrated lower mitotic activity $(-39 \%)$ (Figure $2 \mathrm{~g}$ and $\mathrm{h}$ ). Implantation of MDA-VDR-KD cells also resulted in significantly reduced bone destruction (as demonstrated by significantly greater total and cortical bone area compared to MDA-NT; Figure $2 i$ and j) and reduced osteoclast number at the bone/tumor interface (Figure 2k). These results indicate that knockdown of VDR in breast cancer cells changes tumor growth characteristics in vivo regardless of the tissue environment.

VDR knockdown in PC3 cells-in vitro and in vivo studies In order to investigate whether the effects of VDR ablation on cancer cell behavior are reproducible across different types of cancer, we next studied the human prostate cancer cell line, PC3, in analogous experiments. Compared to non-target controls (PC3-NT, cells transfected with non-target RNA), VDR mRNA and protein expression was reduced by $80 \%$ in PC3 cells at $24 \mathrm{~h}$ post plating (PC3-VDRKD) (Figure $3 a$ and $b$ ). Functionally effective ablation of the VDR was again confirmed by a significant reduction in CYP24 expression following stimulation with $10^{-8} \mathrm{~mol} \cdot \mathrm{L}^{-1}$ $1,25(\mathrm{OH})_{2} \mathrm{D}_{3}$ (Figure $\left.3 \mathrm{c}\right)$. The in vitro growth curves of PC3 cells exhibited similar results to those seen with MDA-MB-231 cells: Knockdown of VDR expression significantly reduced PC3 cell growth, while at the same time stimulating cancer cell apoptosis. These changes were independent of the effects of $1,25(\mathrm{OH})_{2} \mathrm{D}_{3}$ and of similar magnitude to those 


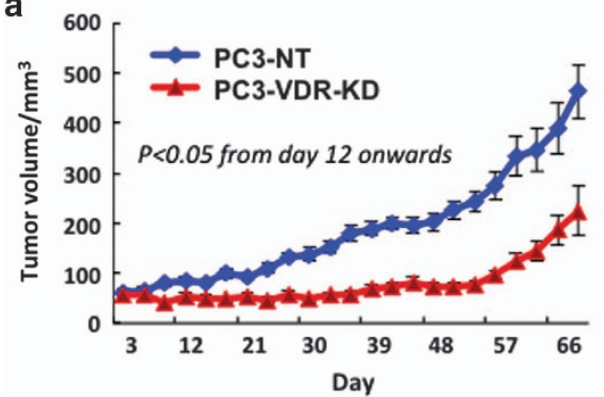

d

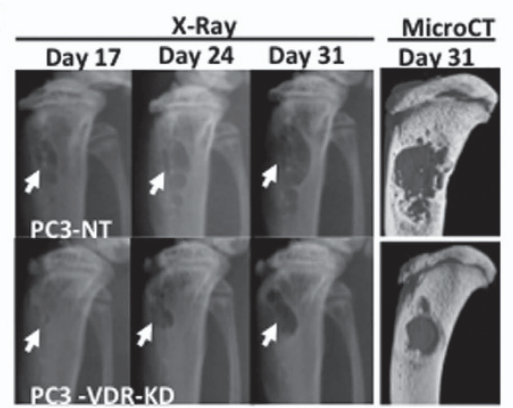

b

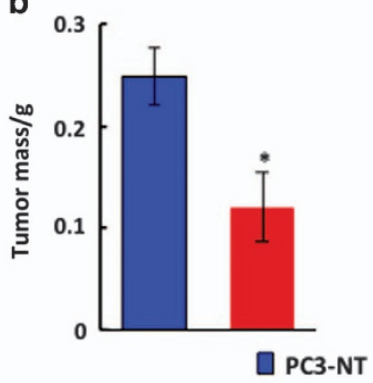

e

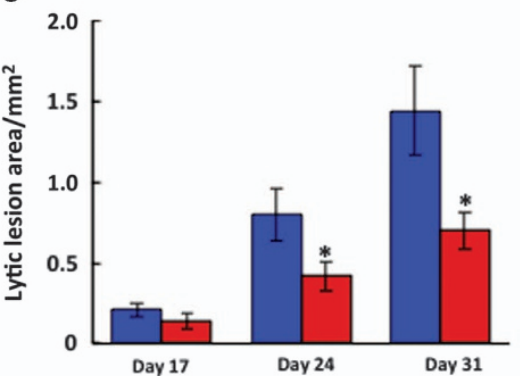

C

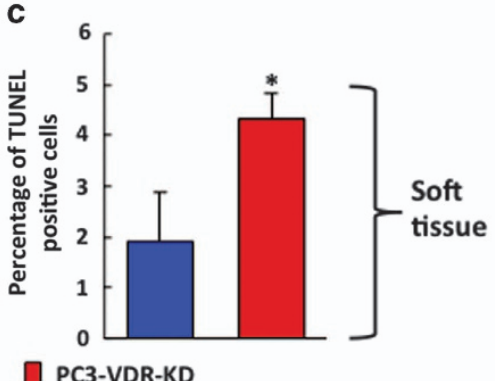

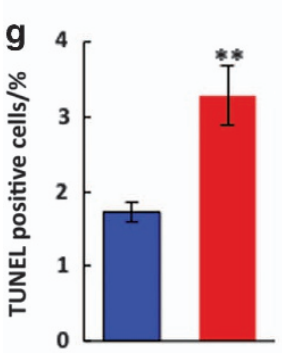
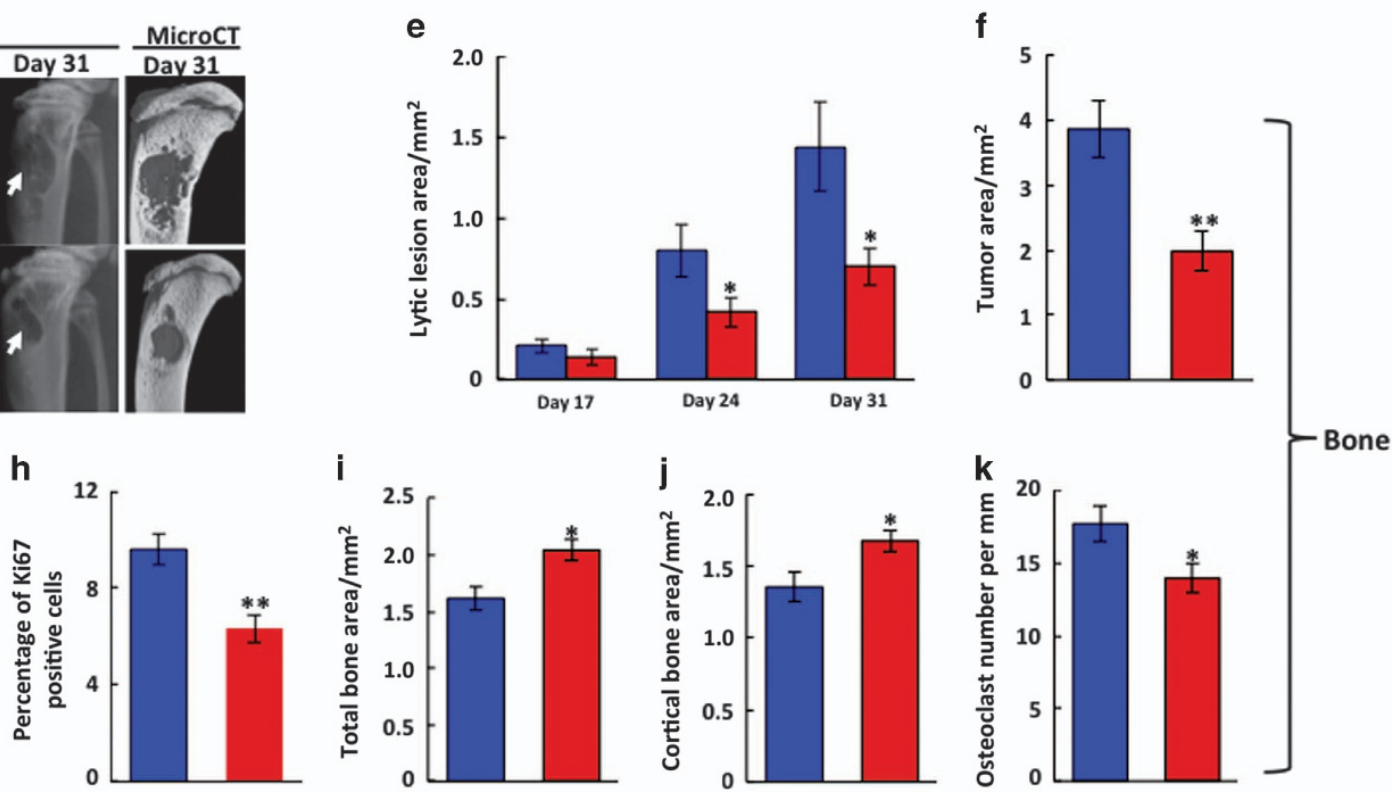

Figure 4. VDR knockdown in PC3 cells reduces tumor growth in vivo. (a-c) Orthotopic implantation (soft tissue, male nude mice). Tumors derived from PC3-VDR-KD cells grew significantly slower than those induced by PC3-NT cells $(n=9)$ (a). At study endpoint (day 69 p.i.) tumor weight $(\mathbf{b})$ was reduced by $40 \%$ and the proportion of apoptotic cells (c) was increased by $125 \%$ in PC3-VDR-KD compared to PC3-NT tumors ( $n=10)$. Asterisks denote significant difference from controls $\left({ }^{*} P<0.05\right)$. Data are mean \pm s.e.m. $(\mathbf{d}-\mathbf{j})$ Intra-tibial implantation: Lytic lesion size $(\mathbf{d}, \mathbf{e})$ and tumor area (f) at endpoint (day 31 p. i.) were significantly smaller in mice implanted with PC3-VDR-KD cells compared to those implanted with PC3-NT cells $(n=12)$. Compared to NT controls, tumors derived from PC3-VDR-KD cells were characterized by increased apoptosis $(\mathrm{g})$ and lower mitotic activity (h), and at the bone/tumor interface exhibited increased total and cortical bone area (i,j) and reduced osteoclast number $(\mathbf{k})$. Asterisks denote significance difference from controls $\left({ }^{*} P<0.05 ;{ }^{* *} P<0.01\right)$. Data are mean \pm s.e.m.

seen when PC3-NT cells were treated with $1,25(\mathrm{OH})_{2} \mathrm{D}_{3}$ (Figure 3d-f). Subsequent in vivo studies in vitamin D-replete nude mice revealed growth patterns comparable to those observed in MDA-MB-231 cells: Thus, in both soft tissue and bone, the growth of tumors derived from PC3-VDR-KD cells was significantly reduced when compared to tumors grown from PC3-NT cells (Figure 4a-k). These results suggest that the effects of VDR ablation on cancer cell growth are similar in human breast and prostate cancer cell lines, and may therefore be generic across different cancers.

Knockdown of VDR in MDA-MB-231 cells reduces the Wnt/ $\beta$-catenin signaling

To further elucidate the function of the VDR in MDA-MB-231 breast cancer cells and the underlying molecular events, we next assayed global gene expression profiles comparing MDA-VDR-KD with MDA-NT cells in vitro. Hierarchical clustering of the top 150 differentially expressed genes revealed distinctive gene expression patterns between MDA-VDR-KD and MDA-NT cells (Figure 5a). Pathway enrichment analysis demonstrated that genes within the Wnt/ $\beta$-catenin pathway were all downregulated in VDR knockdown cells (Figure 5b). Expression of these genes was further validated by real-time RT-PCR, establishing significant downregulation of relevant genes most of which are downstream of $\beta$-catenin (Figure $5 c$ ). Western blot analysis indicated that both cytoplasmic and nuclear $\beta$-catenin protein levels were reduced in MDA-VDR-KD compared to MDA-NT cells. Treatment with $1,25(\mathrm{OH})_{2} \mathrm{D}_{3}$ induced nuclear $\beta$-catenin protein levels in MDA-NT but not in MDA-VDR-KD cells (Figure $5 d$ ). This reduced $\beta$-catenin protein levels could 
a

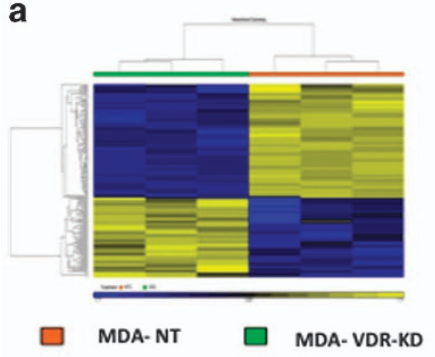

b

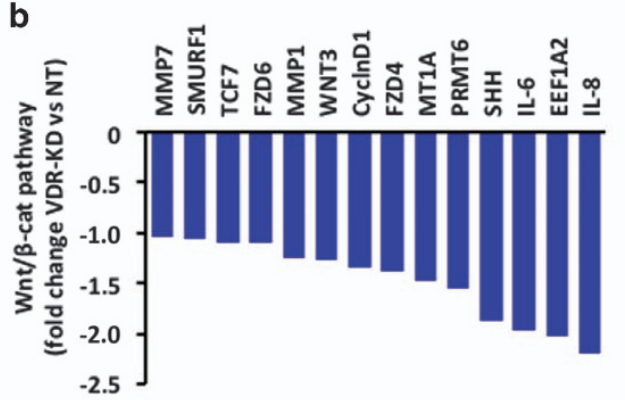

C

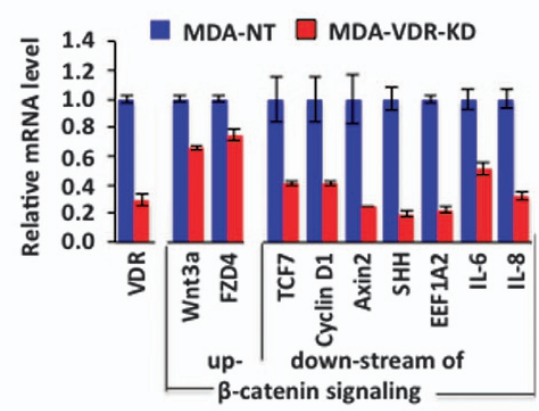

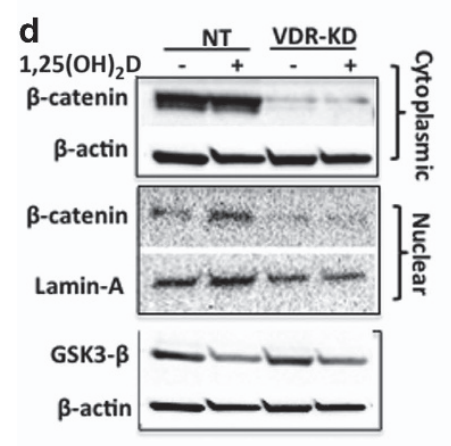

g

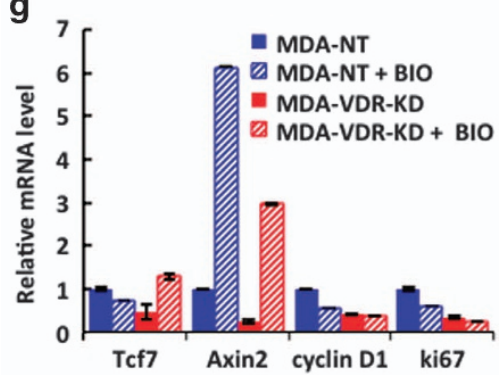

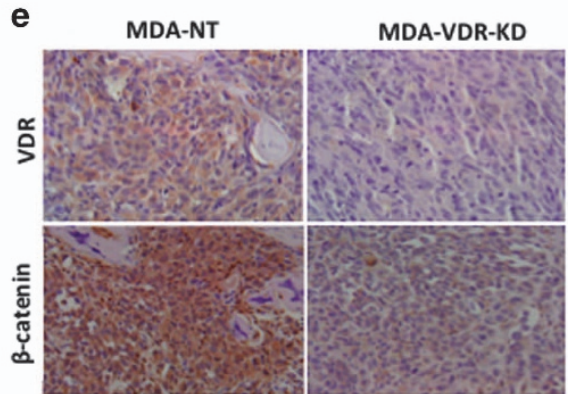

f
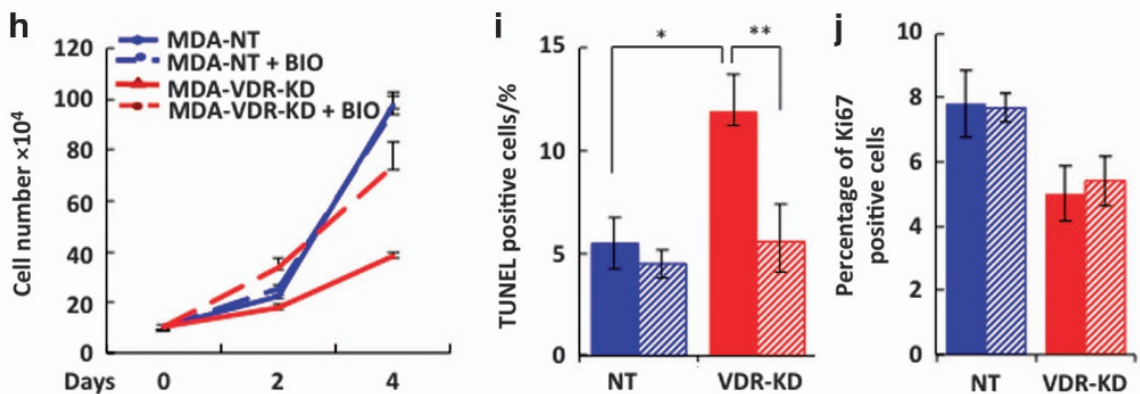

Figure 5. Knockdown of the VDR in MDA-MD-231 breast cancer cells downregulates Wnt/ $\beta$-catenin signaling pathway. (a) Hierarchical clustering of 121 differentially expressed genes $(P<0.05)$ between MDA-VDR-KD compared to MDA-NT cell lines (microarray data set) showed distinctive expression patterns. The three lanes represent gene array patterns derived from three separate cultures of the same cell line (MD-NT or MDA-VDRKD) cultured in identical conditions for the same amount of time. (b) From this list, candidate genes belonging to the Wnt/ $\beta$-catenin pathway, downstream of $\beta$-catenin were shown to be downregulated. (c) qRT-PCR was used to validate these genes whereby reflecting processes in decreased proliferation and increased apoptosis. (d,e) Both cytoplasmic and nuclear $\beta$-catenin protein levels were reduced in MDA-VDR-KD compared to MDA-NT cells. Treatment with $10^{-8} \mathrm{~mol} \cdot \mathrm{L}^{-1} 1,25(\mathrm{OH})_{2} \mathrm{D}_{3}$ induced nuclear $\beta$-catenin protein levels in MDA-NT but not in MDA-VDR-KD cells while GSK-3 $\beta$ expression remained unchanged in $1,25(\mathrm{OH})_{2} \mathrm{D}_{3}$-treated MDA-NT and MDA-VDR-KD cells (d). Reduced $\beta$-catenin protein levels in tumors derived from VDR knockdown cells relative to NT controls (IHC stain, e). (f-j) Inhibition of GSK-3 $\beta$ via treatment of VDR-NT and VDR-KD cells with $1 \mu \mathrm{mol} \cdot \mathrm{L}^{-1} \mathrm{BIO}$ resulted in increased expression levels of $\beta$-catenin protein (f) as well as Axin2, cyclin D1 and Ki67 mRNA (g). Inhibition of GSK-3 $\beta$ was associated with increased growth of MDA-VDR-KD cells (h), significantly reduced apoptosis (i) but unchanged proliferation of VDRKD cells, as assessed by Ki67 expression (j). Asterisks denote significance difference from controls $\left({ }^{*} P<0.05\right.$; $\left.{ }^{* *} P<0.01\right)$. Data are mean \pm s.e.m.

be due to, at least in part, the reductions of Wnt3a and FZDR, the upstream initiative genes (Figure $5 c$ ) but were not due to GSK-3 $\beta$ as its expression is not altered in MDA-VDR$K D$ cells (Figure $5 d$ ).

Ex vivo analyses of tumor tissue confirmed that $\beta$-catenin protein levels were reduced in tumors derived from VDR knockdown cells relative to NT controls (Figure $5 e$ ). There is solid evidence to indicate that aberrant activation of Wnt/ $\beta$-catenin signaling inhibits cell apoptosis while promoting cell proliferation. ${ }^{26-28}$ Thus, the slower growth of tumors generated by VDR knockdown cells may be due to a reduction in $W n t / \beta$-catenin activation. To test this hypothesis, we treated the cells with the GSK-3 $\beta$ inhibitor, 6-bromoindirubin-3'-oxime (BIO, Sigma), to stabilize and therefore enhance $\beta$-catenin levels. ${ }^{23}$ At concentrations of 1 and $10 \mu \mathrm{mol} \cdot \mathrm{L}^{-1}, \mathrm{BIO}$ elevated cytoplasmic $\beta$-catenin and increased nuclear $\beta$-catenin protein levels in both MDA-NT and MDA-VDR-KD cells (Figure 5f). Consequently, Axin2 mRNA levels were increased 6- and 3-fold in BIO-treated NT and VDR-KD cells, respectively (Figure $5 \mathrm{~g}$ ). 
In contrast, BIO had no effect on mRNA expression of Cyclin D1 or Ki67 (Figure 5g). Growth curve analyses showed that treatment of VDR knockdown cells with $\mathrm{BIO}$ restored cell growth to approximately $70 \%$ of NT controls (Figure 5h). Consistent with the results for mRNA expression (Figure 5g), immunohistochemistry for Ki67 confirmed that treatment of NT or VDR-KD cells with BIO had no effect on proliferation (Figure 5j). In contrast, treatment of MDA-VDR$\mathrm{KD}$ cells with $\mathrm{BIO}$ resulted in a significant reduction in the proportion of apoptotic cells, similar to the levels observed in NT cells (Figure 5i).

\section{DISCUSSION}

Our in vitro and in vivo studies demonstrate that the VDR has a function in promoting the growth of breast and prostate cancer cells, independent of its cognate ligand, $1,25(\mathrm{OH})_{2} \mathrm{D}$. This previously unrecognized function of the VDR is operational both within and outside the bone microenvironment. Mechanistically, we established that knockdown of the VDR in cancer cells interferes with the $W n t / \beta$-catenin signaling pathway. Thus, VDR knockdown is associated with a robust reduction in cytoplasmic $\beta$ catenin protein levels, resulting in enhanced cell apoptosis and reduced proliferation rates. Of note, stabilization of $\beta$-catenin and hence re-activation of $\beta$-catenin signaling in VDR knockdown cells partly restored cell growth, mostly through inhibition of cell apoptosis.

We previously reported that vitamin $D$ deficiency promotes the growth of human breast and prostate cancer cells in bone. 5,8,10,13 This acceleration in cancer cell growth was, at least in part, attributable to the effects of vitamin $D$ deficiency on the bone microenvironment, as hypovitaminosis D-via an increase in parathyroid hormone secretion-induces a significant increase in osteoclast-mediated bone resorption. 5,8,10,13 In addition, treatment with $1,25(\mathrm{OH})_{2} \mathrm{D}_{3}$ inhibits breast and prostate cancer cell growth in vitro and in vivo. ${ }^{8,10}$ This and the fact that inhibition of bone remodeling failed to completely reverse the pro-proliferative effects of vitamin $D$ deficiency provided evidence that vitamin $D$ signaling may be directly involved in the control of tumor growth in bone. Disrupting vitamin D signaling in cancer cells would therefore be expected to promote cell proliferation and tumor growth, similar to the effects of vitamin D deficiency.

However, contrary to this assumption and our expect ations, we found that silencing of the VDR in breast and prostate cancer cell lines consistently resulted in reduced cell growth and increased apoptosis in vitro. Importantly, these effects were seen not only in the presence but also in the absence of $1,25(\mathrm{OH})_{2} \mathrm{D}_{3}$. Furthermore, the effects of VDR knockdown on tumor growth, cancer cell proliferation and apoptosis observed in vitro were fully reproducible in vivo, evident not only in bone but also in soft tissues, and independent of whether human breast or prostate cancer cell lines were used. The fact that the VDR knockdown cells are insensitive to treatment with $1,25(\mathrm{OH})_{2} \mathrm{D}_{3}$ is particularly relevant to the in vivo experiments, as these were performed in vitamin D-replete mice, thus providing evidence that the reduction in tumor growth seen in vivo with VDR-KD cells must be independent of vitamin D. Taken together, our findings indirectly suggest that the VDR holds hitherto unknown functions that promote cancer cell growth independent of its ligand.

Most of the known biological effects of $1,25(\mathrm{OH})_{2} \mathrm{D}$ are mediated through binding to the VDR. Ligand binding causes the VDR to form a heterodimer with the retinoid $X$ receptor and to translocate from the cytoplasm to the nucleus, where the complex binds to vitamin D-responsive elements in the regulatory region of its target genes. ${ }^{15}$ In the absence of vitamin D, the VDR is mostly retained in the cytoplasm, ${ }^{29-30}$ however, recent evidence suggests that shuttling of the unliganded VDR to the nucleus produces basal transcriptional activity via binding to co-repressor or co-activators. ${ }^{30-35}$ Global chromatin immunoprecipitation (ChIP) analyses have also indicated that a significant number of DNA-binding sites are occupied by the VDR in the absence of its cognate ligand. ${ }^{36}$

There is little data available regarding a potential unliganded function of the VDR. Previous studies in skin suggest that the unliganded VDR plays a role in the context of normal keratinocyte stem cell function (through interaction with the canonical Wnt pathway)..$^{20,37-38}$ The fact that ablation of VDR expression in cancer cells results in a marked inhibition of cell and tumor growth raises the possibility of the unliganded VDR being involved in the regulation of cancer cell proliferation and apoptosis. However we acknowledge that this conclusion cannot be seen as definitive due to incomplete VDR ablation. Our data indicate that the proapoptotic and anti-proliferative effects of VDR knockdown are mediated through inhibition of the Wnt/ $\beta$-catenin signaling pathway. Indeed, stabilizing $\beta$-catenin in VDR-KD cells partially restored the growth of these cancer cells. In this context, it was interesting to note that in vitro, BIO-induced stabilization of $\beta$-catenin reversed the effect of VDR-KD on cell apoptosis but not on cell proliferation (for example, Ki67, cyclin DI expression). Also, compared to NT controls, the expression of interleukin-6 (IL-6) and IL-8 mRNA was significantly reduced in breast cancer cells with disrupted VDR signaling. We have previously shown that IL-6 mediates direct paracrine-autocrine signaling between cells of the osteoblast lineage and cancer cells, thereby enhancing the growth of breast cancers in bone. ${ }^{22}$ The reduced growth of VDR knockdown cells and tumors derived from such cells may, at least in part, be due to their diminished expression and secretion of interleukins like IL-6. 
Wnt/ $\beta$-catenin signaling plays a crucial role in breast and prostate cancer cell growth. ${ }^{26-28}$ Aberrant activation of the $\mathrm{Wnt} / \beta$-catenin signaling pathway in cancer cells is associated with the modification of pivotal processes such as Wnt expression, $\beta$-catenin stabilization or degradation, and nuclear translocation of $\beta$-catenin. In the nucleus, $\beta$-catenin complexes with T-cell factor and facilitates transcription of target genes activating cell proliferation and inhibiting apoptosis. Currently, it remains to be seen how the VDR interacts with $\beta$-catenin in cancer cells. For example, we did not detect changes in GSK-3 $\beta$ protein levels, suggesting that the low $\beta$-catenin levels observed in VDR knockdown cells may not be due to its degradation. Instead, in cells with disrupted VDR signaling we found significant changes in the expression of genes upstream of $\beta$-catenin (for example, Wnt3a, FZD4), although it appears that these changes would not fully explain the profound reduction in $\beta$-catenin concentrations and signaling.

Clinical research into the role of vitamin D and VDR status in breast and prostate cancer has remained controversial. While it appears that the VDR is present in differentiated breast cancers, ${ }^{39-40}$ the associations between VDR expression, its downstream signaling and patient prognosis or survival still require further clarification. ${ }^{16,18,41-42}$ VDR expression levels may be associated with the transition from benign to invasive breast tumor. ${ }^{40,43-44}$ Some studies showed cancer progression in breast tumors was characterized by reduced CYP27B 1 and increased CYP24A 1 expression, indicating that during the process of malignant transformation the reduction in VDR expression and higher CYP24A 1 levels renders the tumor less sensitive to vitamin D..$^{40,43}$ Our results may help to explain some of the discrepancies between vitamin D status and clinical outcome ${ }^{45-46}$ as tumor behaviour and patient outcome may likely depend on both vitamin D and VDR status. Thus, in the case of vitamin $D$ deficiency, cancer cells may lose the ligand-mediated nuclear signaling effects of the VDR and as a consequence, the unliganded VDR may become the dominant functional form. Hence, in a ligand-depleted context (that is, vitamin D deficiency), the unliganded VDR may be responsible for increased breast cancer cell growth. In the presence of adequate vitamin $D$, increased nuclear VDR localization and reduced unliganded VDR actions could together reduce breast cancer proliferation. It is possible that local production of $1,25(\mathrm{OH})_{2} \mathrm{D}$, dependent on adequate serum 25(OH)D levels and tissue CYP27B1 activity, may be more important than levels of serum $1,25(\mathrm{OH})_{2} \mathrm{D}$ which do not correlate closely with vitamin $D$ status. ${ }^{47}$ These possibilities need to be further investigated by measuring nuclear and unliganded VDR expression in human tumors at different stages of progression and correlating these results with the patient's vitamin D status in a prospective clinical trial. ${ }^{46}$
In conclusion, the current study demonstrates that the unliganded VDR possesses intrinsic functions that control cancer cell growth in a ligand-independent manner through interference with the Wnt/ $\beta$-catenin signaling pathway. Targeting the unliganded VDR may open up new avenues for the development of novel diagnostic and therapeutic approaches in breast and prostate cancer.

\section{Acknowledgements}

We thank Prof Mark Cooper, Ms Sylvia Gasparini and Ms Sarah Kim for their helpful comments in reviewing this paper. We also thank Jeremy Qiao, Difei Deng and Mamdouh Khalil for their technical assistance. Finally, we express our gratitude to Dr Matthew Foley and the staff at the Australian Centre for Microscopy and Microanalysis, The University of Sydney, for their ongoing support and technical assistance. This study was supported by Cancer Institute NSW CDF fellowship (YZ), Cure Cancer Foundation of Australia (YZ), Cancer Council New South Wales (MJS, YZ, HZ, and CRD), Prostate Cancer Foundation of Australia (MJS, YZ, HZ, and CRD), NH and MRC Early Career Fellowship 596870 (YZ) and German Research Foundation HO 5109/2-1 and HO 5109/2-2 (KH).

\section{Competing interests}

The authors declare no conflict of interest.

\section{References}

1 Robinson BD, Sica GL, Liu YF et al. Tumor microenvironment of metastasis in human breast carcinoma: a potential prognostic marker linked to hematogenous dissemination. Clin Cancer Res 2009; 15: 2433-2441.

2 Mundy GR. Metastasis to bone: causes, consequences and therapeutic opportunities. Nat Rev Cancer 2002; 2: 584-593.

3 Weilbaecher KN, Guise TA, McCauley LK. Cancer to bone: a fatal attraction. Nat Rev Cancer 2011; 11: 411-425.

4 Ooi LL, Zheng Y, Stalgis-Bilinski $\mathrm{K}$ et al. The bone remodeling environment is a factor in breast cancer bone metastasis. Bone 2011; 48: 66-70.

5 Zheng $\mathrm{Y}$, Zhou H, Dunstan $\mathrm{C}$ et al. The role of the bone microenvironment in skeletal metastasis. J Bone Oncol 2013; 2: 47-57.

6 Zheng Y, Basel D, Chow SO et al. Targeting IL-6 and RANKL signaling inhibits prostate cancer growth in bone. Clin Exp Metastasis 2014; 31: 921-933.

7 Zheng $\mathrm{Y}$, Zhou H, Fong-Yee $\mathrm{C}$ et al. Bone resorption increases tumour growth in a mouse model of osteosclerotic breast cancer metastasis. Clin Exp Metastasis 2008; 25: 559-567.

8 Zheng Y, Zhou H, Ooi LL et al. Vitamin D deficiency promotes prostate cancer growth in bone. Prostate 2011; 71: 1012-1021.

9 Zheng Y, Zhou H, Modzelewski JR et al. Accelerated bone resorption, due to dietary calcium deficiency, promotes breast cancer tumor growth in bone. Cancer Res 2007; 67: 9542-9548.

10 Ooi LL, Zhou H, Kalak R et al. Vitamin d deficiency promotes human breast cancer growth in a murine model of bone metastasis. Cancer Res 2010; 70: 1835-1844.

11 Coleman RE. Predictive value of bone resorption and formation markers in cancer patients with bone metastases receiving the bisphosphonate zoledronic acid. J Clin Oncol 2005; 23: 4925-4935. 
12 Rizzoli R, Body JJ, Brandi ML et al. Cancer-associated bone disease. Osteoporos Int 2013; 24: 2929-2953.

13 Ooi LL, Zheng Y, Zhou H et al. Vitamin D deficiency promotes growth of MCF-7 human breast cancer in a rodent model of osteosclerotic bone metastasis. Bone 2010; 47: 795-803.

14 Thorne J, Campbell MJ. The vitamin D receptor in cancer. Proc Nutr Soc 2008; 67: 115-127.

15 Bikle DD. Vitamin D: an ancient hormone. Exp Dermatol 2010; 20: 7-13.

16 Berger U, McClelland RA, Wilson $\mathrm{P}$ et al. Immunocytochemical determination of estrogen receptor, progesterone receptor, and 1,25-dihydroxyvitamin D3 receptor in breast cancer and relationship to prognosis. Cancer Res 1991; 51: 239-244.

17 Berger U, Wilson P, McClelland RA et al. Immunocytochemical detection of 1,25-dihydroxyvitamin D3 receptor in breast cancer. Cancer Res 1987; 47: 6793-6799.

18 Ditsch N, Toth B, Mayr D et al. The Association Between Vitamin D Receptor Expression and Prolonged Overall Survival in Breast Cancer. J Histochem Cytochem 2011; 60: 121-129.

19 Zinser GM, McEleney K, Welsh J. Characterization of mammary tumor cell lines from wild type and vitamin D 3 receptor knockout mice. Mol Cell Endocrinol 2003; 200: 67-80.

20 Bikle DD. The vitamin D receptor: a tumor suppressor in skin. Discov Med 2010; 11: 7-17.

21 Yoneda $\mathrm{T}$, Williams PJ, Hiraga $\mathrm{T}$ et al. A bone-seeking clone exhibits different biological properties from the MDA-MB-231 parental human breast cancer cells and a brain-seeking clone in vivo and in vitro.J Bone Miner Res 2001; 16: 1486-1495.

22 Zheng Y, Chow SO, Boernert K et al. Direct crosstalk between cancer and osteoblast lineage cells fuels metastatic growth in bone via autoamplification of IL-6 and RANKL signaling pathways. J Bone Miner Res 2014; 29: 1938-1949.

23 Meijer L, Skaltsounis AL, Magiatis P et al. GSK-3-selective inhibitors derived from Tyrian purple indirubins. Chem Biol 2003; 10: 1255-1266.

$24 \mathrm{Ng} \mathrm{S}$, Lin R, Laybutt D et al. Chronic high-fat diet in fathers programs beta-cell dysfunction in female rat offspring. Nature 2010; 467: 963-966.

25 Pendas-Franco N, Gonzalez-Sancho JM, Suarez Y et al. Vitamin D regulates the phenotype of human breast cancer cells. Differentiation 2007; 75: 193-207.

26 Jiang G, Xiao X, Zeng Y et al. Targeting beta-catenin signaling to induce apoptosis in human breast cancer cells by z-guggulsterone and Gugulipid extract of Ayurvedic medicine plant Commiphora mukul. BMC Complement Altern Med 2013; 13: 203.

27 Yasuhara R, Irie T, Suzuki $\mathrm{K}$ et al. The beta-catenin signaling pathway induces aggressive potential in breast cancer by up-regulating the chemokine CCL5. Exp Cell Res 2015; 338: 22-31.

28 Tan Z, Zheng H, Liu X et al. MicroRNA-1229 overexpression promotes cell proliferation and tumorigenicity and activates Wnt/beta-catenin signaling in breast cancer. Oncotarget 2016; 7: 24076-24087.

29 Huet T, Laverny G, Ciesielski F et al. A vitamin d receptor selectively activated by gemini analogs reveals ligand dependent and independent effects. Cell Rep 2015; 10: 516-526.

30 Prufer K, Racz A, Lin GC et al. Dimerization with retinoid X receptors promotes nuclear localization and subnuclear targeting of vitamin D receptors. J Biol Chem 2000; 275: 41114-41123.
31 Sanchez-Martinez R, Zambrano A, Castillo AI et al. Vitamin D-dependent recruitment of corepressors to vitamin $\mathrm{D} /$ retinoid $\mathrm{X}$ receptor heterodimers. Mol Cell Biol 2008; 28: 3817-3829.

32 Tagami T, Lutz WH, Kumar R et al. The interaction of the vitamin D receptor with nuclear receptor corepressors and coactivators. Biochem Biophys Res Commun 1998; 253: 358-363.

33 Dwivedi PP, Muscat GE, Bailey PJ et al. Repression of basal transcription by vitamin $\mathrm{D}$ receptor: evidence for interaction of unliganded vitamin $\mathrm{D}$ receptor with two receptor interaction domains in RIP13delta1. J Mol Endocrinol 1998; 20: 327-335.

34 Gardiner EM, Esteban LM, Fong C et al. Vitamin D receptor B1 and exon 1d: functional and evolutionary analysis. J Steroid Biochem Mol Biol 2004; 89-90: 233-238.

35 Prufer K, Barsony J. Retinoid X receptor dominates the nuclear import and export of the unliganded vitamin D receptor. Mol Endocrinol 2002; 16: $1738-1751$.

36 Pike JW, Meyer MB, Benkusky NA et al. Genomic determinants of vitamin D-regulated gene expression. Vitam Horm 2016; 100: 21-44.

37 Cianferotti L, Cox M, Skorija K et al. Vitamin D receptor is essential for normal keratinocyte stem cell function. Proc Natl Acad Sci USA 2007; 104: 9428-9433.

38 Beildeck ME, Gelmann EP, Byers SW. Cross-regulation of signaling pathways: an example of nuclear hormone receptors and the canonical Wnt pathway. Exp Cell Res 2010; 316: 1763-1772.

39 Santagata S, Thakkar A, Ergonul A et al. Taxonomy of breast cancer based on normal cell phenotype predicts outcome. J Clin Invest 2014; 124: 859-870.

40 Lopes N, Sousa B, Martins D et al. Alterations in Vitamin D signalling and metabolic pathways in breast cancer progression: a study of VDR, CYP27B1 and CYP24A1 expression in benign \& malignant breast lesions. BMC Cancer 2010; 10: 483.

41 Friedrich M, Axt-Fliedner R, Villena-Heinsen C et al. Analysis of vitamin D-receptor (VDR) and retinoid X-receptor alpha in breast cancer. Histochem J 2002; 34: 35-40.

42 LaPorta E, Welsh J. Modeling vitamin D actions in triple negative/basallike breast cancer. J Steroid Biochem Mol Biol 2014; 144: 65-73.

43 Townsend K, Banwell CM, Guy M et al. Autocrine metabolism of vitamin D in normal and malignant breast tissue. Clin Cancer Res 2005; 11: 3579-3586.

44 Johnson AL, Zinser GM, Waltz SE. Vitamin D3-dependent VDR signaling delays ron-mediated breast tumorigenesis through suppression of beta-catenin activity. Oncotarget 2015; 6: 16304-16320.

45 Manson JE, Mayne ST, Clinton SK. Vitamin D and prevention of cancer - ready for prime time? N Engl J Med 2011; 364: 1385-1387.

46 Chlebowski RT. Vitamin D and breast cancer incidence and outcome. Anticancer Agents Med Chem 2013; 13: 98-106.

47 Adams JS, Hewison M. Extrarenal expression of the 25-hydroxyvitamin D-1-hydroxylase. Arch Biochem Biophys 2012; 523: 95-102.

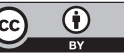

This work is licensed under a Creative Commons Attribution 4.0 International License. The images or other third party material in this article are included in the article's Creative Commons license, unless indicated otherwise in the credit line; if the material is not included under the Creative Commons license, users will need to obtain permission from the license holder to reproduce the material. To view a copy of this license, visit http:/ / creativecommons.org/licenses/by/4.0/

(C) The Author(s) 2017 